\title{
ANÁLISIS DE LA VULNERAB ILIDAD DE LOS HOGARES BOLIVIANOS A LA INSEGURIDAD ALIMENTARIA EN 2015
}

\author{
Alejandra Delgado y Hernán Naranjo Mejía \\ RESUMEN
}

La presente investigación analiza la vulnerabilidad a la inseguridad alimentaria de los hogares bolivianos en el año 2015. Dado que el concepto de inseguridad alimentaria es sumamente complejo, esta investigación centró su atención en la diversidad y calidad de la dieta de los hogares bolivianos (de acuerdo a información de la Encuesta de Hogares 2015) entendiendo que un hogar con una dieta deficiente es más vulnerable a este fenómeno. Por otro lado, tres dimensiones del concepto de seguridad alimentaria (disponibilidad, acceso y uso de alimen tos) fueron la base para encontrar variables que puedan explicar esta situación a nivel del hogar. Un modelo de elección binaria (Probit) fue utilizado para determinar la probabilidad de que un hogarboliviano sea vulnerable y sus resultados muestran la importancia de la mujer, la educación, el estado civil, la edad, la generación de ingreso y las condiciones físicas del hogar para reducir la vulnerabilidad a la inseguridad alimentaria de los hogares. Asimismo, esta investigación halló una interesante relación entre la vulnerabilidad a la inseguridad alimentaria y la localización del hogar y la condición étnica del jefe de hogar; lo cual podría ser explicado por la naturaleza de la agricultura familiar en Bolivia.

Palabras clave: Inseguridad Alimentaria, Hogares, Nutrición, Diversidad Dietética, Bolivia.

DOI: $10.23881 /$ idupbo.017.2-3e 